\title{
A Randomized, Placebo-Controlled GH Trial in Very Preterm Infants Who Were at Risk for Bronchopulmonary Dysplasia and Were Treated with Dexamethasone
}

\author{
MARIANNE W.A. HUYSMAN, WIM C.J. HOP, ADRI H. CROMME-DIJKHUIS, \\ PIETER J.J. SAUER, AND ANITA C.S. HOKKEN-KOELEGA \\ Department of Pediatrics [M.W.A.H.], Division of Neonatology, Division of Cardiology [A.H.C.-D.], and \\ Division of Endocrinology [A.C.S.H.-K.], Erasmus University Medical Center Rotterdam/Sophia \\ Children's Hospital, 3004 BA Rotterdam, The Netherlands; and Department of Biostatistics and \\ Epidemiology [W.C.J.H.], Erasmus University Medical Center Rotterdam, 3000 CB Rotterdam, The \\ Netherlands; Department of Pediatrics [P.J.J.S.], Beatrix Children's Hospital, University Groningen, \\ Groningen, 9700 RB Groningen, The Netherlands; and Department of Pediatrics [M.W.A.H.], Sint
}

Franciscus Gasthuis, Rotterdam, 3004 BA Rotterdam, The Netherlands

\begin{abstract}
Very preterm infants who develop bronchopulmonary dysplasia are often treated with dexamethasone (DEXA) to wean them from the ventilator. As DEXA has growth-suppressive and catabolic effects, which might have long-term consequences on growth and organ development, we investigated whether high-dose GH treatment could overcome these effects. In a randomized, double-blind, placebo-controlled trial, 30 ventilated very low birth weight infants were assigned to receive either $\mathrm{GH}$ or placebo treatment after start of DEXA. DEXA was given for $24 \mathrm{~d}$ (starting dose $0.5 \mathrm{mg} \cdot \mathrm{kg}^{-1}$ $\cdot \mathrm{d}^{-1}$, tapering off every third day). Simultaneously, high-dose $\mathrm{GH}$ $\left(0.3 \mathrm{mg} \cdot \mathrm{kg}^{-1} \cdot \mathrm{d}^{-1}\right)$ or placebo was administered during $6 \mathrm{wk}$. During high-dose DEXA treatment (dose $0.5-0.3 \mathrm{mg} \cdot \mathrm{kg}^{-1} \cdot \mathrm{d}^{-1}$ ), no gain in head circumference, weight, crown-heel length, and knee-heel length occurred in the GH and placebo groups. Growth during the 6-wk study period was not different between the $\mathrm{GH}$ and the placebo groups. Two patients in the placebo group died, but the number and the severity of adverse effects was not statistically
\end{abstract}

\section{ABSTRACT}

different between the $\mathrm{GH}$ and placebo groups. In conclusion, highdose GH treatment did not improve growth in DEXA-treated very preterm infants and thus cannot be recommended to prevent growth failure in these infants. During high-dose DEXA, a complete growth arrest occurred, including stunting of head growth. Growth in head circumference and weight with lower dose DEXA was comparable to growth after discontinuation of DEXA. (Pediatr Res 58: 705$712,2005)$
Abbreviations
BPD, bronchopulmonary dysplasia
DEXA, dexamethasone
IGFBP-3, IGF-binding protein-3
NICU, neonatal intensive care unit
ROP, retinopathy of prematurity
RWTh, relative wall thickness
SGA, small for gestational age

In very preterm infants, the development of bronchopulmonary dysplasia (BPD) is a major problem. According to the latest classification, BPD is evaluated at $36 \mathrm{wk}$ postmenstrual age or at discharge from the neonatal intensive care unit (NICU), whichever comes first, and is defined as a persistent need for supplemental oxygen for at least $28 \mathrm{~d}$ with a persistence of respiratory

Received October 1, 2004; accepted February 24, 2005

Correspondence: Marianne W.A. Huysman, M.D., Ph.D., Department of Pediatrics, Sint Franciscus Gasthuis, Kleiweg 500, P.O. Box 10900, 3004 BA Rotterdam, The Netherlands; e-mail: m.huysman@sfg.nl.

This study was financially supported by a grant from the Revolving Fund from the Erasmus University Medical Center Rotterdam. Recombinant human growth hormone and placebo were supplied by Novo Nordisk A/S Denmark.

DOI: 10.1203/01.PDR.0000180567.94279.AE features, such as retractions, tachypnea, and rales as a result of respiratory disease (1). The incidence of BPD increases from 12\% in infants with a gestational age of $30 \mathrm{wk}$ to $30-40 \%$ in those who are born after a gestational age of 25-26 wk $(2,3)$.

In NICUs, systemic corticosteroids are often given to wean very preterm infants with severe and prolonged respiratory problems from the ventilator (4-6). Many infants who are at risk for development of BPD are treated with dexamethasone (DEXA). DEXA treatment in preterm infants is known to have an inhibiting effect on weight gain as well as linear growth and head circumference (7-11). Follow-up studies suggest impairment in brain growth and persisting growth retardation into childhood (12-16). 
Corticosteroids have a suppressive effect on pituitary GH secretion in children (17). In a previous study, we demonstrated a significant DEXA-induced decline in serum GH levels in ventilated very preterm infants (18). Several studies suggested that the growth-inhibiting effect of DEXA might be overcome by high-dose GH treatment and demonstrated a beneficial effect of GH treatment on linear growth and on neurodevelopment in steroid-treated older children $(19,20)$. As the effects of DEXA in preterm infants might have short-term as well as long-term consequences on longitudinal growth and organ development, we performed a randomized, double-blind, placebo-controlled GH trial in ventilated very preterm infants who were treated with DEXA to evaluate whether recombinant GH overcomes the growth-inhibiting effects of DEXA treatment.

\section{METHODS}

Patients. Between July 1997 and July 2000, 30 ventilated very preterm infants who were born at a gestational age $\leq 32 \mathrm{wk}$ and were at risk for developing BPD were included at the moment DEXA treatment was initiated to wean them from the ventilator. The indication to start DEXA treatment was made by the attending neonatologist and based on a persistent need for artificial ventilation and oxygen dependence accompanied by an abnormal chest x-ray. Patients were excluded when they had a persistent ductus arteriosus, pulmonary infection, or sepsis at randomization or when they had a grade 3 or 4 intraventricular hemorrhage, chromosomal defect, or major congenital anomalies. Patients were also excluded when the mother was treated for an endocrine disorder with $\mathrm{GH}$, thyroxin, or thyreostatic drugs. All patients were admitted to the NICU of the Sophia Children's Hospital in Rotterdam, The Netherlands. The Medical Ethics Committee of the Erasmus University Medical Center approved the study protocol, and written informed consent was obtained from the parents of each child.

Study design and randomization. A randomized, double-blind, placebocontrolled GH trial in ventilated very preterm infants who were treated with DEXA was performed. The primary outcome was growth of head circumference and linear length and gain in weight $6 \mathrm{wk}$ after start of treatment.

Directly after inclusion, all patients started with DEXA treatment and were randomly and blindly assigned to receive recombinant human $\mathrm{GH} 0.3 \mathrm{mg}$. $\mathrm{kg}^{-1} \cdot \mathrm{d}^{-1}$ (Norditropin R; Novo Nordisk A/S Netherlands Alphen)) or placebo treatment (Novo Nordisk A/S) administered once daily by s.c. injection for a period of $6 \mathrm{wk}$. As there is hardly any information about neonatal GH treatment, we used a similar dosage as described in a study that was performed during the neonatal period in term infants who were small for gestational age (SGA) to obtain supraphysiologic serum GH levels (21). GH or placebo

Table 1. Perinatal data of the 30 study patients

\begin{tabular}{lcc}
\hline & DEXA-GH & DEXA-placebo \\
& $\mathrm{N}=15$ & $\mathrm{~N}=15$ \\
\hline Male/female (n) & $7 / 8$ & $11 / 4$ \\
Gestational age (wk) & $27.2(24.6-30.6)$ & $27.3(24.9-29.9)$ \\
Birth weight (g) & $889(580-1335)$ & $847(501-1335)$ \\
Antenatal steroids (n) & 14 & 12 \\
Premature rupture of the & 2 & 4 \\
$\quad$ membranes (n) & 3 & \multicolumn{2}{c}{} \\
Preeclampsia (n) & 6 & 7 \\
Caesarian Section (n) & 1 & 4 \\
Twin pregnancy (n) & $4.6(2.2)$ & $5.3(2.4)$ \\
Apgar 1 min & $7.3(1.4)$ & $8.0(1.3)$ \\
Apgar 5 min & 9 & 14 \\
Respiratory distress syndrome (n) & 10 & 14 \\
Surfactant use (n) & 9 & 14 \\
Patent ductus arteriosus (n) & 6 & 6 \\
Intraventricular haemorrhage grade & & \\
$\quad$ 1-2 (n) & & 0 \\
Intraventricular haemorrhage grade & 0 & \\
$\quad$ 3-4 (n) & & \\
\hline
\end{tabular}

Results are given as median (range) or number of infants. treatment was started within $4-6 \mathrm{~h}$ after start of DEXA. DEXA treatment was started with a dosage of $0.5 \mathrm{mg} \cdot \mathrm{kg}^{-1} \cdot \mathrm{d}^{-1}$, in two doses per day, during $3 \mathrm{~d}$. Thereafter, the dosage was tapered to $0.3 \mathrm{mg} \cdot \mathrm{kg}^{-1} \cdot \mathrm{d}^{-1}$ for $3 \mathrm{~d}$ and gradually tapered every $3 \mathrm{~d}$ to $0.1 \mathrm{mg} \cdot \mathrm{kg}^{-1} \cdot \mathrm{d}^{-1}$ every other day over a $24-\mathrm{d}$ period. When extubation did not succeed, a second course of DEXA was given while $\mathrm{GH}$ or placebo treatment was continued. The day and time of starting DEXA treatment was $t=0$, and the number of days in study was calculated from the start of DEXA.

Study procedures. All patients underwent a physical examination before start of DEXA. Attending neonatologists, investigators, and parents were unaware of the treatment allocation because of the double-blind design.

The attending neonatologist provided routine care and feeding decisions. According to the policy of the NICU, infants were started on parenteral nutrition on the second day of life, and enteral feedings were initiated on day 7.

Serum GH levels were measured, and in infants with an arterial line, a 6-h $\mathrm{GH}$ profile was performed. Because it was considered unethical to withdraw $>5 \%$ of the total blood volume for study purposes, a longer sampling period and more frequent blood sampling was considered unacceptable. Serum IGF-I and IGF-binding protein-3 (IGFBP-3) levels were measured before as well as 3 and 6 wk after start of DEXA.

Severity of respiratory failure at start of DEXA was assessed by calculating the ventilation score (mean airway pressure $X$ inspired fraction of oxygen). Possible adverse effects of DEXA and of GH treatment, such as need for antihypertensive or insulin treatment, cardiac hypertrophy, and incidence and severity of retinopathy of prematurity (ROP), were recorded. Nutritional intake was calculated from the daily nutritional intake.

Cardiologic evaluation. Cardiologic evaluation was performed before, during, and after stopping DEXA treatment. M-mode echocardiography was used according to the recommendations of the American Society of Echocardiography (22). The occurrence of left ventricular hypertrophy was assessed and defined as a relative wall thickness (RWTh) of the left ventricle $>0.2$. RWTh was calculated by dividing the posterior wall thickness of the left ventricle by the left ventricle internal dimension measured at end diastole.

Anthropometric measurements. Weight, recumbent crown-heel length, knee-heel length, and head circumference were measured. All anthropometric measurements were done by two experienced people. Baseline measurements were performed before DEXA was started. Weight was measured daily; head circumference and crown-heel length were measured weekly. Knee-heel length was measured twice a week. The time of measurements was recorded and calculated as hours from the start of DEXA administration.

Crown-heel length was measured using a neonatometer in the incubator, with full extension of the hips and knees and with both heels pressing the end of the neonatometer. The mean of three readings was used for analysis. Weight was measured on an electronic baby scale (TEC, Tokyo Electronic Co., Tokyo, Japan), every day at the same time. Head circumference was measured three times using a standard plastic measuring tape. The mean of three readings was used for analysis. Knee-heel length was measured according to Gibson with a hand-held knemometer (7). The mean of eight readings was used for analysis. The investigator performed the measurements but remained blind for the readings, which were performed and recorded by an observer.

The coefficients of variation for both observers for crown-heel length were 0.3 and $0.4 \%$, for weight were 0.4 and $0.4 \%$, for knee-heel length were 0.6 and $0.7 \%$, and for occipito-frontal head circumference were 0.1 and $0.2 \%$, respectively. Birth weight was expressed as SD scores for gestational age according to the standards of Usher and McLean (23). Small for gestational age was defined as a birth weight SD score $<-2$.

Hormone assays. All hormone determinations were performed in the Endocrine Laboratory of the Erasmus University Hospital Rotterdam, the Netherlands. Serum GH levels were measured using a two-site immunoradiometric assay (ELSA-HGH; CIS bio international, ORIS Group, France). The World Health Organization First International Reference Preparation WHO $80 / 505$ was used as a standard. The intra- and interassay coefficients of variation were $<2.8$ and $<4.4 \%$, respectively.

Serum IGF-I levels were determined by RIA (SM-C-RIA-CT; Biosource Europe SA). Intra- and interassay coefficients of variation were $<6.1$ and $9.9 \%$, respectively. Cross-reactivity with IGF-II, insulin, and GH was 0.2 , $<0.001$, and $<0.01 \%$, respectively.

Serum IGFBP-3 levels were determined using a two-site immunoradiomet-ric assay (IGF-BP3 IRMA, DSL-6600; Diagnostic Systems Laboratories, Webster, TX). Intra- and interassay coefficients of variation were $<3.9$ and $1.9 \%$, respectively.

Statistical analysis. Statistical analyses were performed using SPSS 9.0 for Windows 95 (SPSS software, Chicago, IL) or SAS version 6.12 for Windows (SAS Institute Inc., Cary, NC). Visual inspection of scatter plots of anthropometric data showed stable values during the first week for all parameters but an increase thereafter. Therefore, these data were analyzed using piecewise linear 
Table 2. Clinical data of the 30 study patients

\begin{tabular}{|c|c|c|}
\hline & $\begin{array}{c}\text { DEXA-GH } \\
\mathrm{N}=15 \\
\text { Median (range) }\end{array}$ & $\begin{array}{l}\text { DEXA-placebo } \\
\quad \mathrm{N}=15 \\
\text { Median (range) }\end{array}$ \\
\hline \multicolumn{3}{|l|}{ At randomisation } \\
\hline Postconceptional age (wk) & $30.3(27.6-35.1)$ & $29.0(27.4-33.9)$ \\
\hline Ventilation score & $429(255-880)$ & $450(250-1800)$ \\
\hline Weight $(\mathrm{g})$ & $1101(750-1510)$ & $1035(720-1630)$ \\
\hline Occipito-frontal headcircumference $(\mathrm{cm})$ & $26.5(23.0-29.7)$ & $26.3(22.5-29.6)$ \\
\hline \multicolumn{3}{|l|}{ During 6-weeks study period } \\
\hline Caloric intake $(\mathrm{kcal} / \mathrm{kg} / \mathrm{day}) \S$ & $133.6(17.1)$ & $128.7(21.1)$ \\
\hline Protein intake $(\mathrm{g} / \mathrm{kg} /$ day $) \S$ & $3.4(0.2)$ & $3.5(0.3)$ \\
\hline Number of days on DEXA (days) & $24(22-42)$ & $24(3-36)$ \\
\hline Number of days on artificial ventilation (days) $\dagger$ & $3(1-31)$ & $4(1-30)$ \\
\hline \multicolumn{3}{|l|}{ Follow-up at 36 wk PCA (after study period) } \\
\hline Death $(\mathrm{Y} / \mathrm{N})$ & $0 / 15$ & $2 * / 13$ \\
\hline Need for supplemental O2 at 36 wk PCA (Y/N) & $11 / 4$ & $9 / 4$ \\
\hline ROP grade $3-4(\mathrm{Y} / \mathrm{N})$ & $2 / 13$ & $3 / 11$ \\
\hline Cystic PVL (Y/N) & $0 / 15$ & $1 / 13$ \\
\hline
\end{tabular}

PCA: post conceptional age (wks), O2: oxygen, LVH: left ventricular hypertrophy: defined as Relative Wall Thickness of the left ventricle (posterior wall thickness left ventricle/left ventricle internal dimension) $>0.2$, ROP: retinopathy of prematurity, PVL: periventricular leucomalacia.

* 2 patients died: one patient due to progressive respiratory insufficiency (study day 3) and one patient due to cystic PVL (study day 46).

$\dagger$ after start of DEXA.

$\S$ data expressed in mean (SD).

Table 3. Anthropometric measurements during the 6-week study period

\begin{tabular}{|c|c|c|c|c|c|c|c|c|}
\hline & \multicolumn{4}{|c|}{ DEXA-GH } & \multicolumn{4}{|c|}{ DEXA-placebo } \\
\hline & \multirow[b]{2}{*}{ Week 1} & \multicolumn{3}{|c|}{ Week 2-6 } & \multirow[b]{2}{*}{ Week 1} & \multicolumn{3}{|c|}{ Week 2-6 } \\
\hline & & $\begin{array}{c}\text { During } \\
\text { DEXA§ }\end{array}$ & $\begin{array}{c}\text { After } \\
\text { DEXAI }\end{array}$ & Total & & $\begin{array}{c}\text { During } \\
\text { DEXA§ }\end{array}$ & $\begin{array}{c}\text { After } \\
\text { DEXAI }\end{array}$ & Total \\
\hline Weight & -2.7 & 16.2 & 15.8 & 15.8 & -3.1 & 15.3 & 16.0 & 15.6 \\
\hline $\mathrm{g} / \mathrm{kg} /$ day & $(-7.8 ; 2.4)$ & $(14.6 ; 17.8)$ & $(14.2 ; 17.4)$ & $(12.5 ; 19.1)$ & $(-7.8 ; 1.6)$ & $(13.5 ; 17.1)$ & $(14.2 ; 17.8)$ & $(12.3 ; 18.9)$ \\
\hline CHL & -0.5 & 0.8 & $1.2 *$ & 1.0 & -0.5 & 0.9 & 1.1 & 1.0 \\
\hline $\mathrm{mm} / \mathrm{wk}$ & $(-1.3 ; 1.5)$ & $(2.1 ; 3.2)$ & $(3.2 ; 4.2)$ & $(2.8 ; 3.5)$ & $(-1.3 ; 1.3)$ & $(2.2 ; 3.4)$ & $(3.0 ; 3.9)$ & $(2.7 ; 3.4)$ \\
\hline $\mathrm{HC}$ & -0.0 & 1.0 & 1.0 & 1.0 & -0.3 & 1.0 & 0.9 & 0.9 \\
\hline $\mathrm{cm} / \mathrm{wk}$ & $(-0.3 ; 0.2)$ & $(0.9 ; 1.2)$ & $(0.9 ; 1.1)$ & $(0.9 ; 1.1)$ & $(-0.6 ; 0.1)$ & $(0.8 ; 1.1)$ & $(0.8 ; 1.0)$ & $(0.8 ; 1.0)$ \\
\hline
\end{tabular}

Results are given as mean $(95 \% \mathrm{CI})$ increase per day or week.

CHL: crown-heel length, KHL: knee-heel length, HC: head circumference.

$\S$ period from week 2 until stop DEXA, II period after stop of DEXA, * $\mathrm{p}=0.028$, ** $\mathrm{p}=0.022$, significant increase versus during DEXA.

regression ("broken-stick" method), with a breakpoint at day 7 (24). In a secondary analysis, the effect of discontinuation of DEXA was investigated using the same method. This was done by allowing for a second breakpoint for each patient individually at the day of discontinuation of DEXA. These analyses were done using repeated measurements ANOVA, and calculations for this particular analysis were done with SAS software (random coefficients model from SAS PROC MIXED).

Weight and hormone values were logarithmically transformed before analysis to obtain approximate normal distributions. Percentages were compared using Fisher's exact test. Two-sided $p \leq 0.05$ were considered significant.

\section{RESULTS}

Clinical characteristics. Thirty patients were included in the study. Fifteen patients were treated with $\mathrm{GH}$, and 15 patients received placebo, in addition to DEXA. The clinical data of the patients before start and during the study are shown in Tables 1 and 2. Three infants in the GH and five infants in the placebo group were born SGA. Most infants received $24 \mathrm{~d}$ of DEXA, but one infant in the GH group and one infant in the placebo group received a second course DEXA. In the placebo group, one patient died at day 3 as a result of progressive respiratory insufficiency.

Anthropometry. We first analyzed the anthropometric data for differences between treatment and placebo groups. No significant differences were found for any of the measures (Table 3). We then pooled the data from both groups to evaluate the effect of dexamethasone treatment. We found that 


\section{DEXA - GH}

A

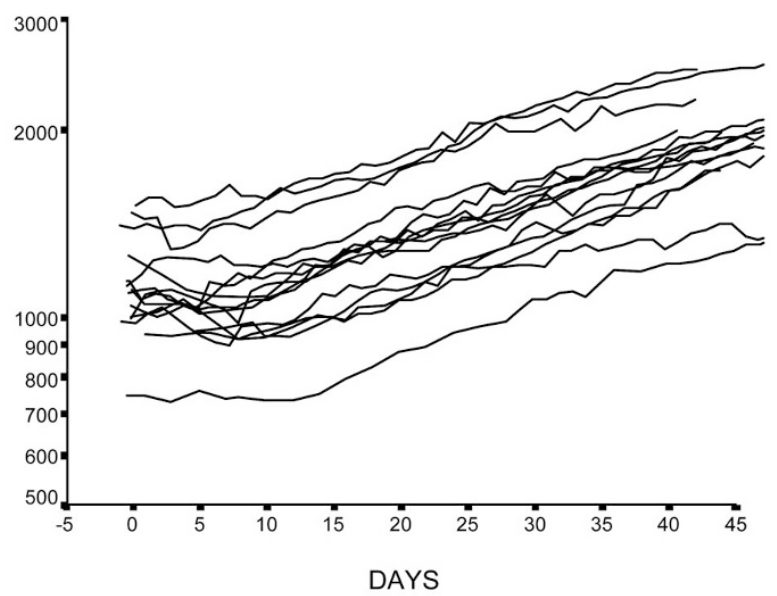

B

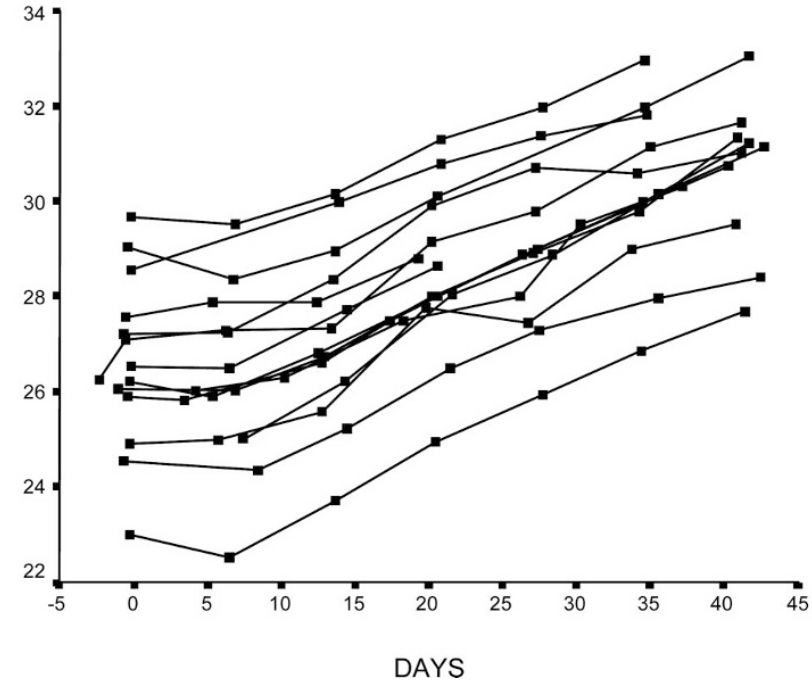

\section{DEXA - placebo}
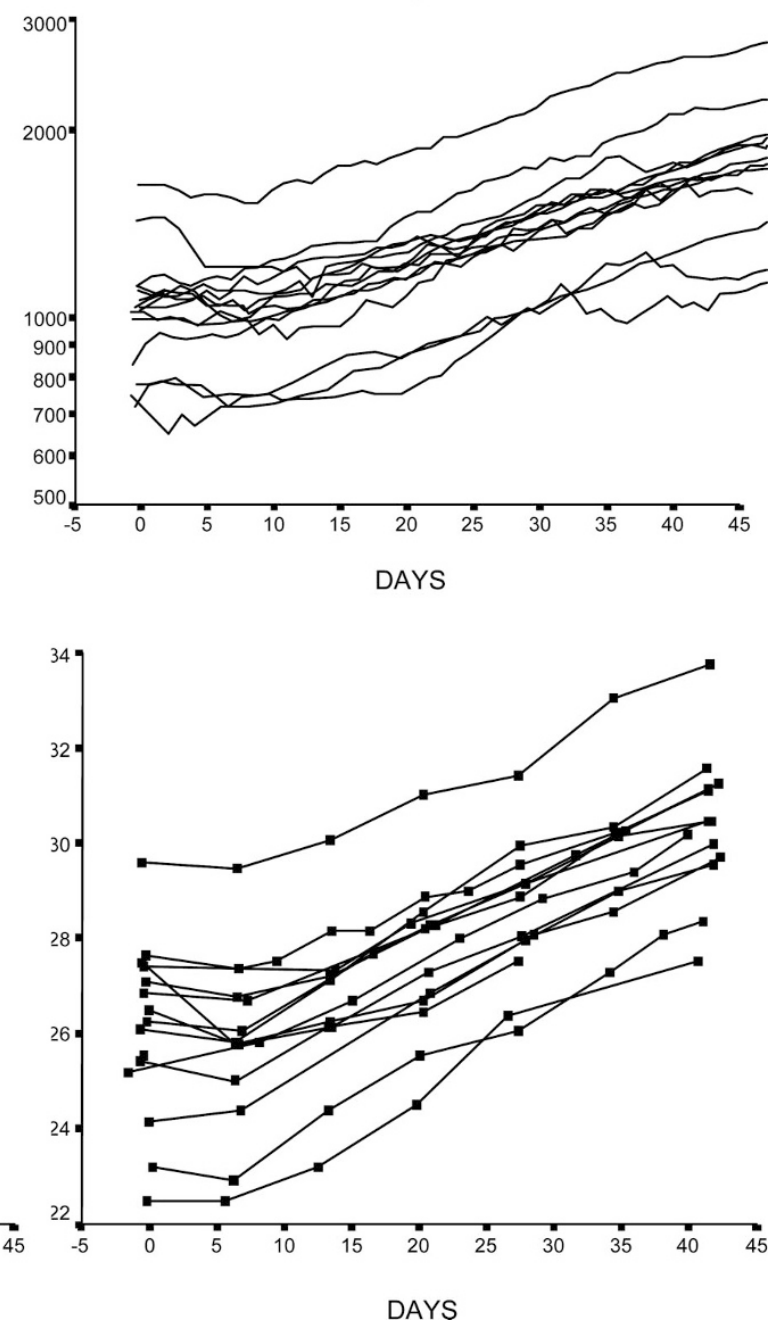

Figure 1. Growth during the 6-wk study period. (A) Weight (expressed in g). (B) Head circumference (expressed in $\mathrm{cm}$ ). (C) Crown-heel length (expressed in $\mathrm{cm})$. (D) Knee-heel length (expressed in $\mathrm{mm}) v s$ time (days) after start of DEXA.

during the first week on DEXA (dose 0.5 to $0.25 \mathrm{mg} \cdot \mathrm{kg}^{-1}$. $\mathrm{d}^{-1}$ ), there was no increase in any measurement, showing a complete growth arrest including head growth. During the remainder of the study period, increases in weight, head circumference, crown-heel length, and knee-heel length were significantly different from week 1 (all $p<0.001$; Fig. 1).

Comparing growth after cessation of DEXA with growth while on lower doses of DEXA (weeks 2 and 3) showed no significant increase in head circumference and weight in both treatment groups and no increase in crown-heel length and knee-heel length in the placebo group (Table 3). In the GH group, the increase in crown-heel length and knee-heel length after discontinuation of DEXA was significantly higher than during weeks 2 and 3 on DEXA ( $p=0.028$ and $p=0.022$, respectively).

Serum hormone levels. In six infants who were treated with GH, serum GH profiles were performed (Fig. 2). Serum GH levels in the GH group varied between 1.4 and $518 \mu \mathrm{g} / \mathrm{L}$. High GH levels after administration of GH were followed by a rapid decline to $<5 \mu \mathrm{g} / \mathrm{L}$, just before administration of the next dose. In three patients serum GH half-life was $1.9,5.2$, and $5.5 \mathrm{~h}$, respectively.
In both the GH and placebo groups, neither start nor discontinuation of DEXA resulted in a change in serum IGF-I levels from baseline. At day 21, serum IGF-I levels were not significantly different between the groups (Table 4). Serum IGFBP-3 levels during DEXA were higher compared with baseline levels in both groups $(p<0.02)$ but not different between the groups $(p=0.15)$. Serum IGFBP-3 levels did not change after discontinuation of DEXA in both groups $(p=0.46)$.

Adverse effects. The number of infants who received antihypertensive or insulin treatment was similar in the placeboand GH-treated groups. Two patients in the placebo group and none in the GH group died. The number of infants who developed BPD or severe ROP on follow-up until 36 wk postconceptional age was not different between the groups. Left ventricular hypertrophy measured by RWTh of the left ventricle occurred in the majority of infants in both groups during DEXA treatment and was not significantly different between the groups.

\section{DISCUSSION}

This is the first placebo-controlled GH study to measure the effect of GH versus placebo in combination with DEXA treat- 

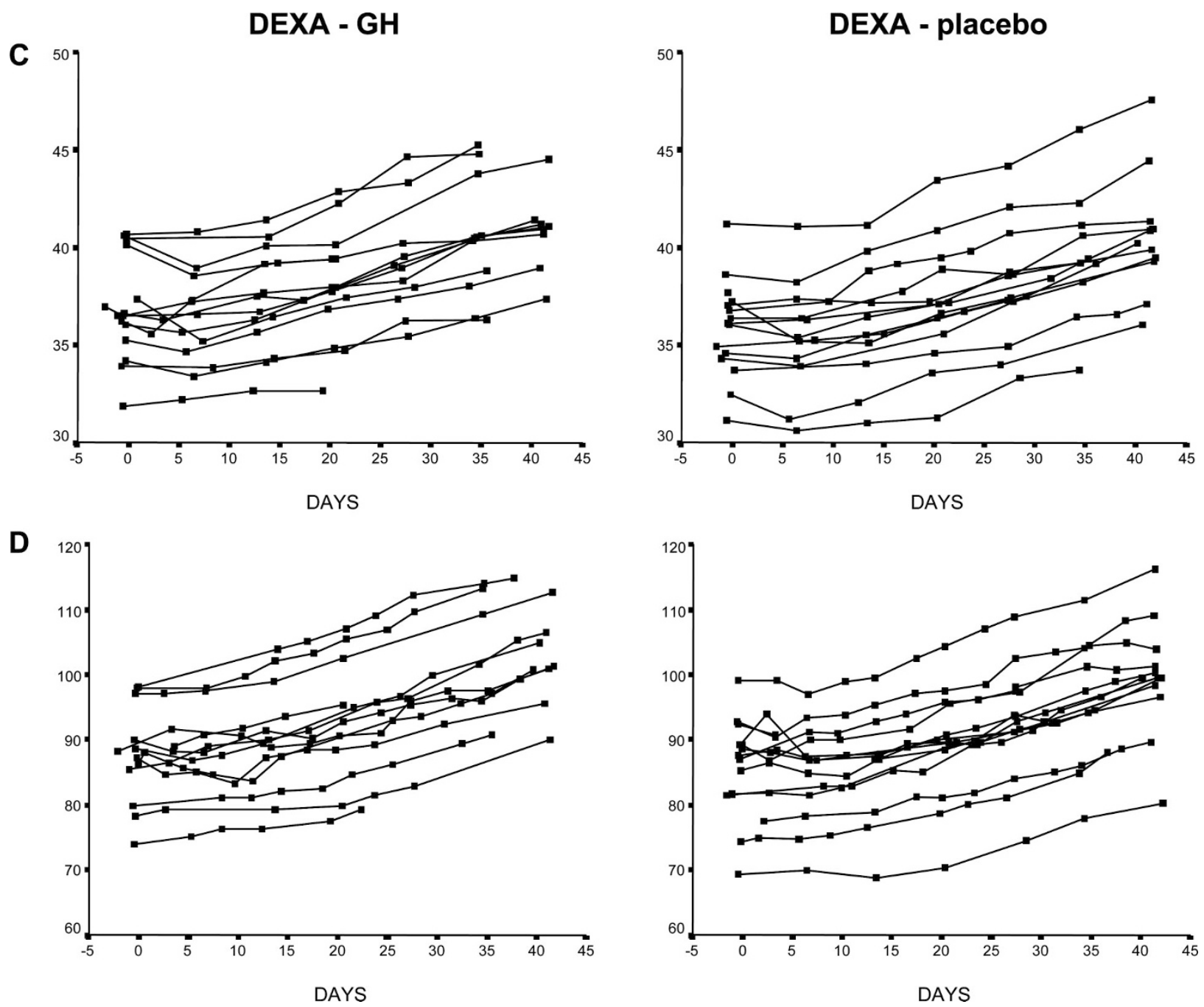

Figure 1. (Continued)

ment on growth in very preterm infants. There were four major findings in this study. First, GH treatment had no effect in preventing impairment of growth in DEXA-treated preterm infants when a GH dose of $0.3 \mathrm{mg} \cdot \mathrm{kg}^{-1} \cdot \mathrm{d}^{-1}$ was given for a 6-wk period. Second, a complete growth arrest as a result of DEXA treatment was associated with high-dose DEXA treatment. Third, growth in head circumference and weight during lower dose of DEXA was comparable to growth after cessation of DEXA. Fourth, after discontinuation of DEXA, an increase in linear growth (crown-heel length and knee-heel length) was observed.

Nowadays, the use of DEXA in very preterm infants to wean them from the ventilator is an area of great concern, especially when high doses of glucocorticoids are given. DEXA treatment in very preterm infants has been associated with reduced cerebral cortical gray matter, an arrest of alveolarization of the lungs, catabolic effects, alteration of skeletal metabolism, and cessation of growth (7-16,25-27). Despite these substantial concerns, DEXA is still administered to very preterm infants to wean them from the ventilator when clinical and radiologic signs of BPD develop and conservative treatment such as increased ventilation settings, fluid restriction, diuretics, antibiotics, and inhalation therapy has failed (28). The starting dose of DEXA that is usually given to very preterm infants is $0.5 \mathrm{mg} \cdot \mathrm{kg}^{-1} \cdot \mathrm{d}^{-1}$ for $3 \mathrm{~d}$, which might be equivalent to as much as $20 \mathrm{mg} / \mathrm{kg}$ or more of hydrocortisone in biologic effect.

In the present study, weight, crown-heel length, knee-heel length, and head circumference were measured accurately with minimal intra- and interobserver variations, which allowed evaluation of growth on a weekly basis. During the first week, a high dose of DEXA $(0.5 \mathrm{mg} / \mathrm{kg})$ for $3 \mathrm{~d}$ was given, followed by a dose of $0.3 \mathrm{mg} / \mathrm{kg}$ for $3 \mathrm{~d}$ and $0.25 \mathrm{mg} / \mathrm{kg}$ for $3 \mathrm{~d}$. When the daily DEXA dose was decreased to $<0.25$ or $0.20 \mathrm{mg}$. $\mathrm{kg}^{-1} \cdot \mathrm{d}^{-1}$, the growth of head circumference and weight was similar to the growth rate after discontinuation of DEXA. Apparently, there was a dose-effect relationship of DEXA as described in older children (29). Because the present studies show an association between DEXA treatment in the neonatal period and a decrease in cortical gray matter and neurologic impairment, the fact that we did find stunted growth of head circumference with the use of high-dose DEXA ( 0.5 to $0.25 \mathrm{mg}$ $\cdot \mathrm{kg}^{-1} \cdot \mathrm{d}^{-1}$ ) might have major implications for future use of DEXA in very preterm infants. 


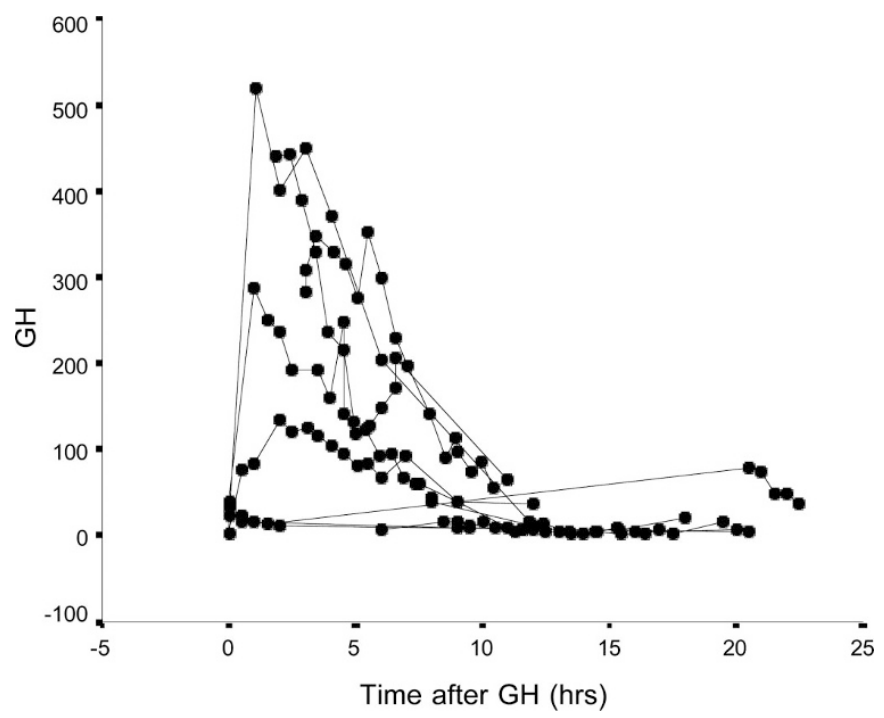

Figure 2. Serum GH levels in DEXA-treated infants who received GH. Serum GH levels are expressed in $\mu \mathrm{g} / \mathrm{L} v s$ time after administration of $\mathrm{GH}$ (in h).

Several studies reported reduced growth during DEXA treatment in preterm infants $(7,9,11,30,31)$. Although the duration of DEXA treatment varied in these studies, the initial dose of DEXA used in most studies was 0.5 to $0.6 \mathrm{mg} \cdot \mathrm{kg}^{-1} \cdot \mathrm{d}^{-1}$ and gradually tapered off as in our study. In one study in 10 preterm infants, reduced growth of weight, head circumference, and crown-heel length was observed during the first 2 wk on DEXA compared with weeks 3 and 4. Although there was a great variation in duration of DEXA treatment (10-70 d), these data suggest that the dose of DEXA was negatively correlated with growth (31). In another study, comparing the effect of a 6-wk course of DEXA with a 3-d pulse of DEXA every $10 \mathrm{~d}$, the higher cumulative dose in the 6-wk DEXA group resulted in a lower increase in knee-heel length during the first 2 wk of DEXA (9). In addition to these studies, the study by Stark et al. (11) starting with a lower DEXA dose of $0.15 \mathrm{mg} \cdot \mathrm{kg}^{-1} \cdot \mathrm{d}^{-1}$ within $24 \mathrm{~h}$ after birth showed a decrease in weight and head circumference at $36 \mathrm{wk}$ postmenstrual age. Although which dose of DEXA induces a reduction of growth was not described precisely, all studies point to a possible dose-related and maybe an age-related effect of DEXA.

Very limited data are available on $\mathrm{GH}$ treatment in the neonatal period in either term or preterm infants. In one study, treatment with recombinant $\mathrm{GH}\left(0.3 \mathrm{mg} \cdot \mathrm{kg}^{-1} \cdot \mathrm{d}^{-1}\right)$ in preterm infants who were born SGA did not have any effect on growth and body composition during the neonatal period (21). It is known that the GH/IGF-I ratio in infants who are born SGA is higher than in infants who are born appropriate for gestational age during the neonatal period, suggesting a higher GH insensitivity in infants who are SGA compared with appropriate for gestational age, at least directly after birth. Therefore, the results of the GH study in infants who were SGA cannot be applied directly to other preterm infants. Although three infants in the GH group were born SGA, we believe that this cannot explain our results.

On the basis of our results, it can be concluded that $\mathrm{GH}$ treatment, even in a high dose, is not effective to improve growth in very preterm infants during DEXA treatment in the neonatal period. For comparison, the administered $\mathrm{GH}$ dose was 10 times the dose prescribed to GH-deficient children. Possible explanations for this result might be the high dose of glucocorticoids and/or GH insensitivity in very preterm infants.

The DEXA dose used in preterm infants is much higher than the dosages used in older, prednisone-treated children in which $\mathrm{GH}$ treatment was shown to be effective. Improvements of weight and height velocity with $\mathrm{GH}$ treatment are reported in children who receive glucocorticoids dosages equivalent to $0.1-0.5 \mathrm{mg} \cdot \mathrm{kg}^{-1} \cdot \mathrm{d}^{-1}$ prednisone in chronic diseases such as asthma, lupus, and autoimmune colitis and after renal transplantation $(20,32,33)$. Also in these older children, the effect of GH treatment is dependent on the dose of glucocorticoids used (34).

Serum GH levels that were measured in our infants who received GH treatment were very high but did not result in higher IGF-I levels, indicating GH insensitivity in these preterm infants, which might explain the lack of effect of $\mathrm{GH}$ treatment. The mechanisms by which DEXA induces growth retardation are still poorly understood. In an earlier study in very preterm infants, we did not find a decline in serum IGF-I levels $2 \mathrm{~d}$ after starting DEXA, and also in the present study, no change in serum IGF-I during DEXA treatment was observed (18). It might well be that serum IGF-I levels do not decline during DEXA treatment and that the observed growth inhibition by DEXA in earlier studies (35) is due to a direct effect of DEXA on the epiphyseal cartilage by inhibition of the local secretion and paracrine action of IGF-I (36). Prednisone causes in vitro a $46 \%$ fall in IGF-I bioactivity and has a suppressive effect on IGF mRNA in the tibia, liver, lung, and kidney in the rat, without causing significant changes in serum immunoreactive IGF-I levels $(37,38)$. Thus, DEXA-induced

Table 4. Serum IGF-I and IGFBP-3 levels in DEXA-GH and DEXA-placebo treated infants

\begin{tabular}{|c|c|c|c|c|c|c|}
\hline & \multicolumn{3}{|c|}{ DEXA-GH } & \multicolumn{3}{|c|}{ DEXA-placebo } \\
\hline & Baseline & Day 21 & Day 42 & Baseline & Day 21 & Day 42 \\
\hline IGF-I & $\begin{array}{c}39.8 \\
(20.7-96.7)\end{array}$ & $\begin{array}{c}53.2 \\
(9.9-95.6)\end{array}$ & $\begin{array}{c}36.0 \\
(9.9-222.6)\end{array}$ & $\begin{array}{c}42.1 \\
(7.7-234.8)\end{array}$ & $\begin{array}{c}30.6 \\
(6.1-65.8)\end{array}$ & $\begin{array}{c}37.5 \\
(17.6-73.4)\end{array}$ \\
\hline IGFBP-3 & $\begin{array}{c}0.7 \ddagger \\
(0.3-3.7)\end{array}$ & $\begin{array}{c}1.3^{*} \\
(0.7-2.2)\end{array}$ & $\begin{array}{r}1.2^{* *} \\
(0.8-3.2)\end{array}$ & $\begin{array}{c}0.5 \\
(0.2-0.9)\end{array}$ & $\begin{array}{r}1.1 * * * \\
(0.4-1.6)\end{array}$ & $\begin{array}{c}1.2 * * * \\
(0.8-1.5)\end{array}$ \\
\hline
\end{tabular}

Results are given as median (range).

Serum levels of IGF-I expressed in $\mathrm{ng} / \mathrm{ml}$, IGFBP-3 in $\mathrm{mg} / \mathrm{l}$.

$* \mathrm{p}<0.01$, ** $\mathrm{p}<0.02$, *** $\mathrm{p}<0.001$, versus baseline.

$\ddagger \mathrm{p}<0.05$ between both groups. 
inhibition of local IGF-I gene expression might be one of the mechanisms of growth retardation as well.

No difference in the occurrence of adverse effects such as cardiac hypertrophy, hyperglycemia, hypertension, and retinopathy and mortality was found between the GH and the placebo groups. Two patients in the placebo group died. Insulin requirement because of hyperglycemia occurred in both groups and was most likely caused by insulin resistance as a result of DEXA. GH treatment did not increase the need for insulin and did not result in an increase in cardiac hypertrophy compared with the placebo group. This in contrast to adults, in whom a low dose of $\mathrm{GH}$ increases left ventricular mass and an excess of $\mathrm{GH}$ is associated with cardiac hypertrophy $(39,40)$. In our GH-treated patients, we did not find an increase in severe ROP, although recent studies suggest an association between the persistence of high $\mathrm{GH}$ levels in preterm infants and the development of severe retinopathy (41). Although treatment with $\mathrm{GH}$ did not result in a positive effect on growth in the short term, we are planning a long-term follow-up to investigate whether there is any effect on growth, neurodevelopment, and lung function.

In conclusion, $\mathrm{GH}$ treatment had no effect in preventing impairment of growth in DEXA-treated preterm infants when a GH-dose of $0.3 \mathrm{mg} \cdot \mathrm{kg}^{-1} \cdot \mathrm{d}^{-1}$ was given for a 6 -wk period. Despite GH treatment, no growth in head circumference, weight, crown-heel length, and knee-heel length occurred during high-dose DEXA treatment. Therefore, the use of GH in the neonatal period cannot be recommended to prevent growth failure in DEXA-treated preterm infants. Second, a complete growth arrest, including stunting of head growth, occurred during high-dose DEXA treatment $\left(0.5-0.25 \mathrm{mg} \cdot \mathrm{kg}^{-1} \cdot \mathrm{d}^{-1}\right)$. Growth in head circumference and weight with lower doses of DEXA was comparable to growth after discontinuation of DEXA, indicating a dose-related growth-limiting effect of DEXA.

Acknowledgments. We thank Novo Nordisk A/S Denmark for supplying placebo and recombinant human $\mathrm{GH}$ for this randomized, double-blind trial. We thank W. Rietveld for the development of the knemometer for use in the incubator.

\section{REFERENCES}

1. Jobe AH, Bancalari E 2001 Bronchopulmonary dysplasia. Am J Respir Crit Care Med 163:1723-1729

2. El-Metwally D, Vohr B, Tucker R 2000 Survival and neonatal morbidity at the limits of viability in the mid 1990s: 22-25 wks. J Pediatr 137:616-622

3. Lemons JA, Bauer CR, Oh W, Korones SB, Papile LA, Stoll BJ, Verter J, Temprosa M, Wright LL, Ehrenkranz RA, Fanaroff AA, Stark A, Carlo W, Tyson JE, Donovan EF, Shankaran S, Stevenson DK 2001 Very low birth weight outcomes of the National Institute of Child Health and Human Development neonatal research network, January 1995 through December 1996. NICHD Neonatal Research Network. Pediatrics 107:e1

4. Halliday HL, Ehrenkranz RA, Doyle LW 2003 Early postnatal ( $<96$ hours) corticosteroids for preventing chronic lung disease in preterm infants. Cochrane Database Syst Rev (1):CD001146

5. Halliday HL, Ehrenkranz RA, Doyle LW 2003 Moderate early (7-14 days) postnatal corticosteroids for preventing chronic lung disease in preterm infants. Cochrane Database Syst Rev (1):CD001144

6. Halliday HL, Ehrenkranz RA, Doyle LW 2003 Delayed (> 3 weeks) postnatal corticosteroids for chronic lung disease in preterm infants. Cochrane Database Syst Rev (1):CD001145

7. Gibson AT, Pearse RG, Wales JK 1993 Growth retardation after dexamethasone administration: assessment by knemometry. Arch Dis Child 69:505-509
8. DeRegnier RA, Guilbert TW, Mills MM, Georgieff MK 1996 Growth failure and altered body composition are established by one month of age in infants with bronchopulmonary dysplasia. J Nutr 126:168-175

9. Bloomfield FH, Knight DB, Harding JE 1998 Side effects of 2 different dexamethasone courses for preterm infants at risk of chronic lung disease: a randomized trial. J Pediatr 133:395-400

10. Ehrenkranz RA, Younes N, Lemons JA, Fanaroff AA, Donovan EF, Wright LL, Katsikiotis V, Tyson JE, Oh W, Shankaran S, Bauer CR, Korones SB, Stoll BJ, Stevenson DK, Papile LA 1999 Longitudinal growth of hospitalized very low birth weight infants. Pediatrics 104:280-289

11. Stark AR, Carlo WA, Tyson JE, Papile LA, Wright LL, Shankaran S, Donovan EF, Oh W, Bauer CR, Saha S, Poole WK, Stoll BJ 2001 Adverse effects of early dexamethasone in extremely low-birth-weight infants. National Institute of Child Health and Human Development Neonatal Research Network. N Engl J Med 344:95101

12. Davidson S, Schrayer A, Wielunsky E, Krikler R, Lilos P, Reisner SH 1990 Energy intake, growth, and development in ventilated very-low-birth-weight infants with and without bronchopulmonary dysplasia. Am J Dis Child 144:553-559

13. Robertson CM, Etches PC, Goldson E, Kyle JM 1992 Eight year school performance, neurodevelopmental and growth outcome of neonates with bronchopulmonary dysplasia: a comparative study. Pediatrics 89:365-372

14. Murphy BP, Inder TE, Huppi PS, Warfield S, Zientara GP, Kikinis R, Jolesz FA, Volpe JJ 2001 Impaired cerebral cortical gray matter growth after treatment with dexamethasone for neonatal chronic lung disease. Pediatrics 107:217-221

15. Huysman WA, de Ridder M, de Bruin NC, van Helmond G, Terpstra N, Van Goudoever JB, Sauer PJ 2003 Growth and body composition in preterm infants with bronchopulmonary dysplasia. Arch Dis Child Fetal Neonatal Ed 88:F46-F51

16. Yeh TF, Lin YJ, Lin HC, Huang CC, Hsieh WS, Lin CH, Tsai CH 2004 Outcomes at school age after postnatal dexamethasone therapy for lung disease of prematurity. N Engl J Med 350:1304-1313

17. Hokken-Koelega AC, Stijnen T, de Muinck Keizer-Schrama SMPF, Blum WF, Drop SLS 1993 Levels of growth hormone, insulin-like growth factor-I (IGF-1) and -II, IGF-binding protein-1 and -3, and cortisol in prednisone-treated children with growth retardation after renal transplantation. J Clin Endocrinol Metab 77:932-938

18. Huysman WA, Hokken-Koelega AC, Hop WC, Sauer PJ 2003 Effect of dexamethasone treatment on serum GH, IGF-I and the binding proteins IGFBP-1 and -3 in ventilated very preterm infants. Pediatr Res 54:37-43

19. Klaus G, Jux C, Fernandez P, Rodriquez J, Himmele R, Mehls O 2000 Suppression of growth plate chondrocyte proliferation by corticosteroids. Pediatr Nephrol 14:612 615

20. Hokken-Koelega AC, Stijnen T, de Ridder MA, de Muinck Keizer-Schrama SM, Wolff ED, de Jong MC, Donckerwolcke RA, Groothoff JW, Blum WF, Drop SL 1994 Growth hormone treatment in growth-retarded adolescents after renal transplant. Lancet 343:1313-1317

21. van Toledo-Eppinga L, Houdijk EC, Cranendonk A, Delemarre-Van de Waal HA, Lafeber HN 1996 Effects of recombinant human growth hormone treatment in intrauterine growth-retarded preterm newborn infant on growth, body composition and energy expenditure. Acta Paediatr 85:476-481

22. Silverman NH 1993 Quantitative methods to enhance morphological information using ultrasound. In: Pediatric Echocardiography. Williams and Wilkins, Baltimore, pp 42-45

23. Usher R, McLean F 1969 Intrauterine growth of liveborn Caucasian infants at sea level: standards obtained from measurements in 7 dimensions of infants born between 25 and 44 weeks of gestation. J Pediatr 74:901-910

24. Neter J, Wasserman W 1974 Piecewise linear regression. In: Irwin RD (ed) Applied Linear Statistical Models. Homewood, IL, pp 313-316

25. Brownlee KG, Ng PC, Henderson MJ, Smith M, Green JH, Dear PR 1992 Catabolic effect of dexamethasone in the preterm baby. Arch Dis Child 67:1-4

26. Van Goudoever JB, Wattimena JDL, Carnielli VP, Sulkers EJ, Degenhart HJ, Sauer PJ 1994 Effect of dexamethasone on protein metabolism in infants with bronchopulmonary dysplasia. J Pediatr 124:112-118

27. Crofton PM, Shrivastava A, Wade JC, Stephen R, Kelnar CJH, Mcintosh N, Lyon AJ 2000 Effects of dexamethasone treatment on bone and collagen turnover in preterm infants with chronic lung disease. Pediatr Res 48:155-162

28. American Academy of Pediatrics, Committee on Fetus and Newborn, Canadian Paediatric Society, Fetus and Newborn Committee 2002 Postnatal steroids to treat or prevent chronic lung disease in preterm infants. Pediatrics 109:330-338

29. Jabs K, Sullivan EK, Avner ED, Harmon WE 1996 Alternate-day steroid dosing improves growth without adversely affecting graft survival or long-term graft function. A report of the North American Pediatric Renal Transplant Cooperative Study. Transplantation 61:31-36

30. Shrivastava A, Lyon AJ, McIntosh N 1998 Effect of dexamethasone on mineral balance and bone mineralisation in preterm infants with chronic lung disease. Early Hum Dev 51:82A-83A

31. Skinner AM, Battin M, Solimano A, Daaboul J, Kitson HF 1997 Growth and growth factors in premature infants receiving dexamethasone for bronchopulmonary dysplasia. Am J Perinatol 14:539-546

32. Allen DB, Julius JR, Breen TJ, Attie KM 1998 Treatment of glucocorticoid-induced growth suppression with growth hormone. National Cooperative Growth Study. J Clin Endocrinol Metab 83:2824-2829

33. Sanchez CP, Goodman WG, Brandli D, Goldenhersh M, Murray C, Carlton E, Hahn T, Salusky IB 1995 Skeletal response to recombinant human growth hormone (rhGH) in children treated with long-term corticosteroids. J Bone Miner Res 10:2-6

34. Rivkees SA, Danon M, Herrin J 1994 Prednisone dose limitation of growth hormone treatment of steroid-induced growth failure. J Pediatr 125:322-325 
35. Baron J, Huang Z, Oerter KE, Bacher JD, Cutler GB Jr 1992 Dexamethasone acts locally to inhibit longitudinal bone growth in rabbits. Am J Physiol 263:E489E492

36. Jux C, Leiber K, Hügel U, Blum W, Ohlsson C, Klaus G, Mehls O 1998 Dexamethasone impairs growth hormone (GH)-stimulated growth by suppression of local insulin-like growth factor (IGF)-I production and expression of GH- and IGF-Ireceptor in cultured rat chondrocytes. Endocrinology 139:3296-3305

37. Unterman TG, Phillips LS 1985 Glucocorticoid effects on somatomedins and somatomedin inhibitors. J Clin Endocrinol Metab 61:618-626

38. Luo JM, Murphy LJ 1989 Dexamethasone inhibits growth hormone induction of insulin-like growth factor-I (IGF-I) messenger ribonucleic acid (mRNA) in hypoph- ysectomized rats and reduces IGF-I mRNA abundance in the intact rat. Endocrinology 125:165-171

39. Fazio S, Cittadini A, Biondi B, Palmieri EA, Riccio G, Bone F, Oliviero U, Sacca L 2000 Cardiovascular effects of short-term growth hormone hypersecretion. J Clin Endocrinol Metab 85:179-182

40. Link K, Bülow B, Westman K, Salmonsson EC, Eskilsson, Erfurth EM 2001 Low individualized growth hormone $(\mathrm{GH})$ dose increased renal and cardiac growth in young adults with childhood onset GH deficiency. Clin Endocrinol (Oxf) 55:741-748

41. Hikino S, Ihara K, Yamamoto J, Takahata Y, Nakayama H, Kinukawa N, Narazak Y, Hara T 2001 Physical growth and retinopathy in preterm infants: involvement of IGF-I and GH. Pediatr Res 50:732-736 